\title{
The effect of drought stress on inbreeding depression in four populations of the Mediterranean outcrossing plant Crepis sancta (Asteraceae)
}

\author{
PIERRE-OLIVIER CHEPTOU, ANDRÉ BERGER, ALAIN BLANCHARD, \\ CHRISTIAN COLLIN \& JOSÉ ESCARRE \\ Centre d'Ecologie Fonctionnelle et Evolutive (CNRS) 1919 Route de Mende, F-34293 Montpellier Cedex 05, France
}

\begin{abstract}
The effect of physiological stress on the magnitude of inbreeding depression in plants has been the subject of few studies and is currently controversial because of contradictory results. We measured the inbreeding depression at three drought stress levels, precisely defined by a preliminary physiological experiment. We also tested the hypothesis that more highly self-compatible populations exhibit reduced inbreeding depression due to purging of deleterious mutations. The study was conducted on two populations of the annual and allogamous plant Crepis sancta collected from the French Mediterranean region and two other populations from marginal areas with various self-incompatibility levels. Drought stress did not increase inbreeding depression in terms of plant mortality but significantly increased the inbreeding depression for the date of first flowering, number of heads per plant and relative growth rate. The most self-fertile marginal population showed an absence of inbreeding depression in most of the measured traits indicating that purging could have taken place in this population. The three others populations showed relatively low and similar estimates of inbreeding depression $(\delta \approx 0.35)$. The relatively low values obtained compared to the results found in allogamous plants suggests that the absence of competition for $C$. sancta in our experiment probably underestimated the effects of inbreeding in natural populations where competition occurs.
\end{abstract}

Keywords: between-population variation, Crepis sancta, drought stress, inbreeding depression.

\section{Introduction}

The decrease in fitness due to the effects of inbreeding (inbreeding depression) is a subject of major evolutionary importance. Darwin (1876) postulated that it could have an important role in the evolution of mating systems in plants. Fisher (1941) demonstrated that in the absence of inbreeding depression, a gene causing selfing would spread in an automatic way because of its $50 \%$ transmission advantage compared to an outcrossing gene (cost of outcrossing). The balance between these two antagonistic forces, inbreeding depression and the cost of outcrossing, is considered a central factor in the evolution of mating systems (Charlesworth \& Charlesworth, 1987). For this reason inbreeding depression has been particularly well studied in hermaphroditic plants (reviewed in Husband \& Schemske, 1996). Two genetic hypotheses have been proposed to explain inbreeding

*Correspondence. E-mail: cheptou@cefe.cnrs-mop.fr depression. The overdominance hypothesis reasons that heterozygous loci have a better fitness than both homozygotes, whereas the partial-dominance hypothesis proposes that the lower fitness of inbred progenies is due to the expression of recessive deleterious mutations which would be masked in the heterozygous state. Under the partial-dominance hypothesis, it is predicted that inbreeding depression will decrease with selfing, due to the purging process, whereas the overdominance hypothesis predicts that inbreeding depression will increase with selfing rate (Charlesworth \& Charlesworth, 1987). Empirical data show that selfers are more often associated with low inbreeding depression whereas outcrossers have a high inbreeding depression (Husband \& Schemske, 1996) as expected under the partial dominance hypothesis.

Nevertheless, although the genetic basis of inbreeding depression has been well studied in theoretical models (Byers \& Waller, 1999), the effects of environmental conditions, that can provide a source of variation, have 
not often been taken into account. Recent empirical studies suggest that stressful conditions could enhance inbreeding depression (Charlesworth \& Charlesworth, 1987; Uyenoyama et al., 1993). For instance, higher inbreeding depression and heterosis have been documented in agricultural plants under adverse conditions (Wright, 1977). Thus, experiments in optimal growth conditions could underestimate inbreeding depression and do not reveal its real effects in natural populations. This problem is of real importance because it could lead to an underestimate of the selective effect of inbreeding in natural populations and to a misunderstanding of mating systems' evolution. Nevertheless, the possibility that stressful conditions enhance inbreeding depression remains subject to debate because of contradictory results (Norman et al., 1995). Stress can occur under a wide range of natural conditions (competition, nutrient availability, drought) and there is no a priori reason why all stress types should produce the same effect on inbreeding depression. Very few studies have characterized the nature of stress applied to plants (Norman et al., 1995) and more studies are needed to understand this phenomenon. For example, field experiments generally integrate a complex mixture of abiotic and biotic factors, that are not clearly defined and therefore it is difficult to separate their effects on inbreeding depression.

In this paper we present a study to investigate the effects of drought on the inbreeding depression. The study was conducted on four populations of Crepis sancta (Asteraceae), an annual and colonizing species that is very widespread in the Mediterranean region. Previous investigations on this species have shown that inbreeding depression is greatly enhanced by competition in field conditions (Cheptou et al., 2000).

The first objective of this study was to test whether inbreeding depression was magnified by a specific and abiotic physiological constraint: drought stress, a very common stress in the Mediterranean region (Aschmann, 1973). The severity of drought was related to predawn water potential, which provided a measurable physiological stress that was then applied in a constant way throughout the growing season. This is one of the first studies to investigate the effects of drought, in terms of physiological stress on the magnitude of inbreeding depression.

The second objective of this experiment was to document between-population variation in inbreeding depression resulting from mating system history. Although the species is mostly allogamous, betweenpopulation variation in self-incompatibility has been found (Cheptou et al., 2000; unpubl. data). As mentioned by Mayer et al. (1996), in studying the specific relation between the breeding system and inbreeding depression, it is more relevant to study taxa with similar life history traits. Mating system variation among populations provides such characteristics and can be used to test the efficiency of purging deleterious mutations on a short time scale. The partial breakdown of the self-incompatibility system that occurs in $C$. sancta can be considered to be the result of a selective process on the breeding system towards more selfing, revealing inbreeding history. Furthermore, studies documenting variation in inbreeding depression among self-incompatible or partially self-incompatible species are scarce. We hypothesize that more self-compatible populations should exhibit less inbreeding depression.

\section{Materials and methods}

Crepis sancta (Asteraceae) is a Mediterranean diploid species possessing a partial self-incompatibility system (Cheptou et al., 2000). Reproduction starts early in the spring and lasts 5-8 weeks. Heads can produce from 50 to 100 florets, each potentially giving a fruit (achene). Populations are very abundant in the south of France, where they occur in disturbed habitats such as old fields and roadsides. It has recently colonized new areas further north in France. The characteristics of populations are shown in Table 1 . Populations 1 and 2 were sampled in southern France under a Mediterranean climate near Montpellier. Population 3 came from the Limagne plain (central France). In populations 1, 2 and 3, an average of 30 rosettes were harvested in the field at the beginning of 1998 and

Table 1 Locations and main characteristics of Crepis sancta populations

\begin{tabular}{|c|c|c|c|c|c|}
\hline Population & Location & $\begin{array}{l}\text { First appearance } \\
\text { in the region }\end{array}$ & $\begin{array}{c}\text { Type of } \\
\text { environment }\end{array}$ & $\begin{array}{l}\text { Abundance } \\
\text { in the region }\end{array}$ & Population size \\
\hline Pop. 1 & South of France & 1773 (Thellung, 1910) & Vineyard & Very widespread & $200<n<500$ \\
\hline Pop. 3 & Centre of France & 1930 (Chassagne, 1941) & Vineyard & $\begin{array}{l}\text { The only population } \\
\text { found in } 25 \mathrm{~km} \text { square }\end{array}$ & $n>500$ \\
\hline
\end{tabular}

(C) The Genetical Society of Great Britain, Heredity, 85, 294-302. 
grown in a greenhouse. Population 4 came from a vineyard in western France. Seeds were collected from 20 plants in population 4 in the spring and germinated in a greenhouse.

\section{Crossing design}

In March/April 1998, an average of 30 plants per population were placed in a greenhouse to perform controlled pollination following the procedure described in Cheptou et al. (2000). Three treatments were applied to each plant: (1) no active pollination (to test the possibility of spontaneous self-fertilization); (2) hand self-pollination; (3) pollination between plants of the same population. Each pollination was repeated on two heads. The success of pollinations was analysed from the ratio of the number of seeds to total number of florets in a head (seed/floret ratio). The four populations were pollinated in the same conditions, i.e. an insect-proof greenhouse. Moreover, four selfed progenies for 10 randomly chosen families (in the four populations) were analysed by enzyme electrophoresis (Soltis \& Soltis, 1989) to check the absence of foreign alleles in selfed progenies. Four highly polymorphic loci were screened; Lap (E.C. 3.4.11.1) (4-6 alleles per population), Pgi-1 (E.C. 5.3.1.9) (4-5 alleles), Pgi-2 (5 alleles) and Pgm (E.C. 5.4.2.2) (2-4 alleles). Zymograms of the four loci were consistent with self-fertilization and no nonparental alleles were found.

\section{Stress treatments}

The relevant water stress parameter is not soil water content but soil water potential (Slatyer, 1967). To obtain the relation between soil water content and soil water potential, without disturbing the soil, an indirect biological method was used, based on the assumption that the predawn potential of a plant should be in equilibrium with the soil water potential in the root zone (Slatyer, 1967). In this way, pot weight and the predawn potential of a plant (Helianthus annuus) well known to have a good equilibrium with the soil water potential in the root zone at predawn were related (Cruiziat et al., 1980).

A preliminary experiment on Helianthus annuus was conducted to establish the relation between the predawn water potential and pot water content. One-litre pots with dried soil ( $50 \%$ sterile soil and $50 \%$ compost), with the weight measured to the nearest $0.1 \mathrm{~g}$, were used. Ten pots, with three plants per pot, were grown in a greenhouse until sufficient leaves were available for the measurement of predawn potential; this was measured in a greenhouse.

On nonirrigated pots, predawn water potential was measured twice a day for five consecutive days at water contents ranging from field capacity to wilting point. Each time, predawn water potential was measured in each pot from the mean of three leaves (one per plant) and related to the pot soil weight (corrected for plant weight). Measured potential (in MPa) was plotted against the ratio of soil weight/dry soil weight, and the function describing the data is of the form $y=a x^{-b}$ $\left(R^{2}=0.90 ; P<0.001\right)$.

This curve was used to monitor drought stress in this experiment and to define empirically three stress levels (Fig. 1). The 'low stress treatment' consisted of a pot weight maintained at between 1.28 and 1.37 times the dry pot weight. The 'middle stress treatment' consisted of a pot weight maintained at between 1.15 and 1.19 times the dry pot weight. The 'high stress treatment' consisted of a pot weight maintained at between 1.10 and 1.14 times the dry pot weight. It is important to note that the effect of a physiological stress maintained at a constant level throughout the experiment was tested.

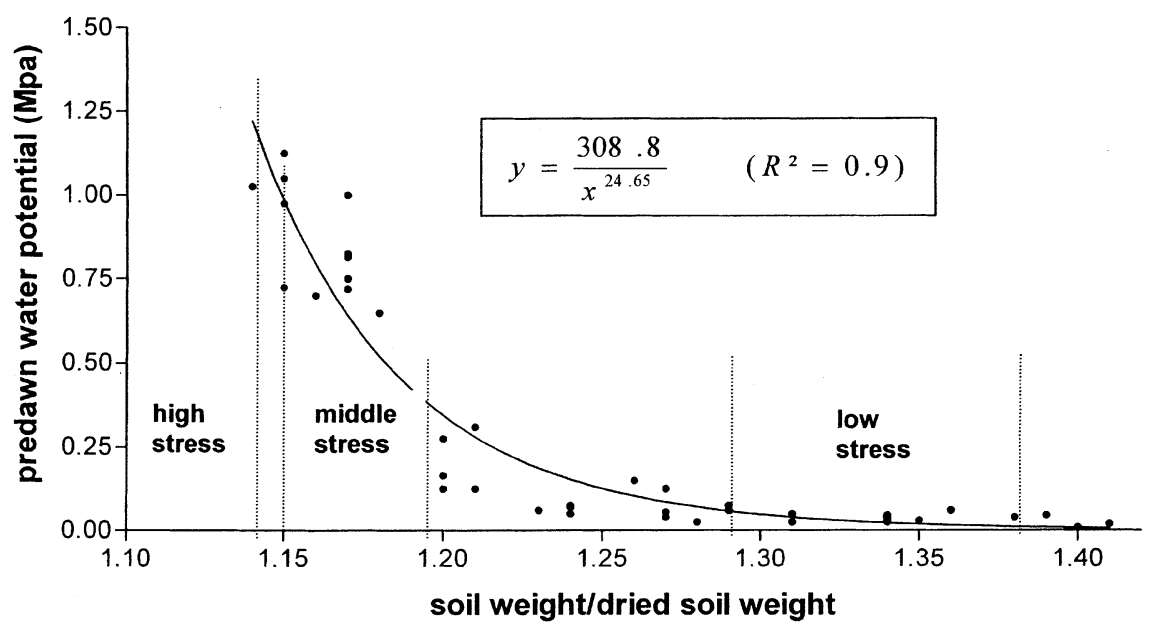

Fig. 1 Curve relating the soil weight/ dried soil weight to the predawn water potential (Mpa) in Helianthus annuus. Dotted lines define predawn water potential thresholds for each treatment. 


\section{Experimental design}

Selfed and outcrossed seeds from experimental crosses were germinated in the middle of December 1998 in a greenhouse. Seeds were germinated with $12 \mathrm{~h}$ artificial light $\left(25^{\circ} \mathrm{C}\right)$ and $12 \mathrm{~h}$ darkness $\left(12^{\circ} \mathrm{C}\right)$. Germination was not included in the analysis of inbreeding depression because of the very high germination success $(>95 \%)$ and low variance in such conditions for both crosses. Families were picked randomly within populations, with the constraint that a sufficient number of seeds per cross was needed. Six, seven, eight and 10 families were used for populations 1, 2, 3 and 4, respectively. Four offspring per cross and per stress (three levels) were used (total of 744 plants). At the beginning of the following February, seedlings were planted in one-litre pots with $820 \mathrm{~g}$ of soil (adjusted to the nearest gram). After 10 days in the greenhouse, pots were placed outdoors and randomized on tables. The plants were acclimatized for 10 days before the period of stress. During this period, seedlings that died were replaced. Nine selfed seedlings, but no outcrossed ones, died. Throughout the experiment, pots were automatically covered when the rain fell. Drought stress was applied at the beginning of March. Every day, 15 randomly chosen pots in each treatment were weighed to estimate their water content. When the lower threshold was reached, automatic watering was released. The between-pot weight variance was low and thus provided a good monitor of the stress. Furthermore, this technique allowed us to move pots randomly in order to minimize position effects on the tables.

Data were collected daily. Mortality before reproduction was checked from the beginning of the stress experiment. Two intermediate measurements of biomass were performed. The first was one week after the beginning of the experiment (T1), and the second when the first flower appeared (T2). The biomass was estimated from the product of the number of leaves times the mean rosette diameter $\left(R^{2}=0.9\right.$; Imbert et al., 1996). The date of first flowering was also measured. Relative growth rate (RGR) was calculated during the period of rosette growth using the formula $\mathrm{RGR}=(\log \mathrm{B} 2-\operatorname{LogB} 1) /(\mathrm{T} 2-\mathrm{T} 1)$, where $\mathrm{B} 1$ (respectively B2) is the estimated biomass in $\mathrm{T} 1$ (respectively $\mathrm{T} 2$ ). T2 - T1 is the period of growth considered and is about one month. At the end of the life cycle, the total number of heads was counted and the above-ground dry biomass was weighed ( 3 days at $50^{\circ} \mathrm{C}$ ). Seed set weight, to the nearest $10^{-4} \mathrm{~g}$, for three heads was measured.

\section{Data analysis}

Statistical analyses were performed using a linear model. The ratio of the number of seeds to the number of florets (seed/floret ratio) was analysed by an ANOVA, after root arcsine transformation (Sokal \& Rohlf, 1995; pp. 421-22) to satisfy analysis of variance assumptions. Two main factors were considered: population and cross type, both assumed as fixed factors.

The number of surviving plants before reproduction is a binomial process. Logistic regression (binomial error and logit link), which is appropriate for these data, was used using the backward suppression of nonsignificant effects method (Crawley, 1993). Factors considered were population, cross and stress treatment.

Quantitative traits were analysed using a mixedANOVA. Population, cross and stress treatment were considered as fixed effects, and the family nested within population factor was considered as random. Mean squares were calculated with Type III sum of squares, and residual error was estimated using Satterwhaites' approximation (SAS, 1989). In order to determine whether inbreeding depression varied with treatment or population, a logarithmic transformation was used to linearize the ratio defining inbreeding depression $\left(\delta=1-w_{\text {self }} / w_{\text {out }}\right)$. This transformation makes the ratio additive and allowed the interpretation of a significant cross-treatment interaction, for instance as a variation of the ratio $\delta$ with treatment. With non-logarithmtransformed data, the interaction indicated that the difference between selfed and outcrossed (but not the ratio) varied with treatments (Johnston \& Schoen, 1994). This transformation was performed for the variables directly linked to fitness, i.e. number of heads per plant, total dry biomass and seed set weight per head. Homoscedasticity was tested with Levene's test. Total fitness was estimated as (survival) $\times$ (number of heads) $\times$ (mean seed set weight of one head) for each plant. However, for this variable, no transformation resulted in satisfactory homoscedasticity in the previous mixed ANOVA, because of the high number of zeros caused by mortality or absence of flowers. Thus, total inbreeding depression: $\delta=1-w_{\text {self }} / w_{\text {out }}$ was calculated using families as replicates. $w_{\text {self }}$ and $w_{\text {out }}$ were calculated from the mean total fitness of the four replicates per family and per cross. Total inbreeding depression was analysed in a two-way ANOVA with population and stress treatment as the main factors. Comparisons of means were performed using the Tukey test (SAS, 1989).

\section{Results}

\section{Analysis of self-fertility: seed/floret ratio}

Two main factors, population and cross type, had a highly significant effect on seed/floret ratio, as did the cross-population interaction (Table 2). The significant interaction indicates that pollination treatments did not 
respond in the same way in the four populations. For instance, the spontaneous pollination ratio was lower than the active self-pollination ratio for two populations, whereas the ratio was equivalent in population 2 and population 3 (Fig. 2). Spontaneous pollination gave

Table 2 ANOva of the effects of cross type and population on seed/floret ratio in Crepis sancta using type III Sum of squares (d.f.: degrees of freedom; MS: mean squares). Data were $\operatorname{Arcsin}(\mathrm{rac})$ transformed to satisfy homoscedasticity

\begin{tabular}{lrc}
\hline Source & d.f. & \multicolumn{1}{c}{ MS } \\
\hline Population & 3 & $6.84^{* * *}$ \\
Cross & 2 & $212.86^{* * *}$ \\
Population $\times$ cross & 6 & $5.00^{* * *}$ \\
Residual & 512 & 0.054 \\
\hline
\end{tabular}

$* * * P<0.001$.

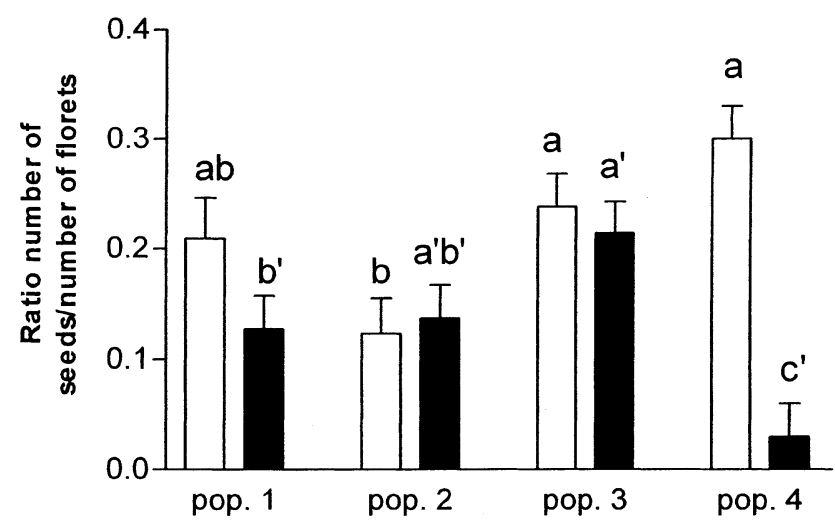

Fig. 2 Mean seed/floret ratio $( \pm \mathrm{SE})$ in the four populations of Crepis sancta. Shaded bars represent spontaneous pollination and open bars represent active self-pollination. The histograms with the same letters do not differ significantly (Tukey test, $P<0.05$ ) for each treatment (with prime: spontaneous pollination, without prime: active self-pollination). fewer seeds than active self pollination. Outcrossing pollination ratio was around $0.6-0.7$ (data not shown).

\section{Analysis of inbreeding depression estimates}

The logistic model applied to survival before reproduction showed a significant population $\times$ stress treatment interaction ( $\log$ likelihood ratio test; hereafter LRT, $\chi^{2}=14.82, \quad$ d.f. $\left.=6, \quad P<0.05\right)$ since population 4 showed a greater effect of drought stress than the other three populations (Table 3). Cross factor was significant (LRT; $\chi^{2}=6.5$, d.f. $=1, P<0.05$ ) because outbred plants had better mean survival than inbred plants. Stress treatment factor was also significant (LRT; $\chi^{2}=21.3$, d.f. $\left.=2, \quad P<0.001\right)$, indicating a higher mortality with increasing drought. A significant cross $\times$ stress treatment interaction also was present (LRT; $\chi^{2}=6.1, P<0.05$ ). The significance of the interaction was caused by the absence of any difference in mortality between crosses in the high stress treatment (Table 3).

The date of first flowering was influenced by population origin (Table 4). Populations 3 and 4, from the limit of the distribution range, flowered on average one week later compared to the populations from the south. The effects of inbreeding and stress were also significant $(P<0.01)$. Inbreeding delayed the date of first flowering as did the drought stress. The family (nested in population) factor was also significant, indicating variability for this character in natural populations. The significance of the family(pop) $\times$ cross interaction indicates that inbreeding effects varied among families.

The stress treatment showed a significant effect on RGR (Table 4, Fig. 3). The cross $\times$ stress treatment interaction was also significant indicating a reduced RGR for inbred plants at high stress. The effect of inbreeding was only significant at the highest stress level

\begin{tabular}{llccc}
\hline & & Low stress & Middle stress & High stress \\
\hline Population 1 & Inbred & $23(24)$ & $22(24)$ & $20(24)$ \\
& Outbred & $23(24)$ & $24(24)$ & $23(24)$ \\
Population 2 & Inbred & $32(32)$ & $32(32)$ & $27(32)$ \\
& Outbred & $32(32)$ & $32(32)$ & $29(32)$ \\
Population 3 & Inbred & $28(28)$ & $26(28)$ & $26(28)$ \\
Population 4 & Outbred & $28(28)$ & $28(28)$ & $24(28)$ \\
& Inbred & $34(40)$ & $38(40)$ & $34(40)$ \\
Fitted survival rate & Outbred & $39(40)$ & $40(40)$ & $36(40)$ \\
& Inbred & 0.94 & 0.95 & 0.86 \\
& Outbred & 0.98 & 0.99 & 0.87 \\
\hline
\end{tabular}

Table 3 Number of surviving plants before reproduction (total number of plants) in the four populations of Crepis sancta for each stress level and fitted survival rate for the three stress levels and both crosses 
Table 4 ANOva of the effects of inbreeding, stress, population and family(population) on measured data using Type III sum of squares (d.f., degrees of freedom; MS, mean squares; RGR, relative growth rate). Number of heads, final dried biomass and seed mass per plant were log transformed

\begin{tabular}{lrccccc}
\hline & d.f. & $\begin{array}{c}\text { Date of first } \\
\text { flower (MS) }\end{array}$ & RGR (MS) & $\begin{array}{c}\text { Number of } \\
\text { heads (MS) }\end{array}$ & $\begin{array}{c}\text { Final dried } \\
\text { biomass (MS) }\end{array}$ & $\begin{array}{c}\text { Seed set mass } \\
\text { per head (MS) }\end{array}$ \\
\hline Population & 3 & $3.38^{* * *}$ & $42.78^{* *}$ & 0.297 & $0.88^{* *}$ & $1.85^{*}$ \\
Cross & 1 & $1.2^{* *}$ & 29.5 & $27.85^{* * *}$ & $2.36^{* * *}$ & $10.8^{* * *}$ \\
Stress & 2 & $0.45^{* *}$ & $1709^{* * *}$ & $398.68^{* * *}$ & $84.75^{* * *}$ & $12.66^{* * *}$ \\
Family (pop) & 27 & $0.3^{*}$ & 6.98 & $11.54^{*}$ & 0.18 & 0.55 \\
Pop $\times$ cross & 3 & 0.28 & $20.06(0.07)$ & 0.99 & 0.05 & $1.12^{*}$ \\
Pop $\times$ stress & 6 & 0.06 & 9.36 & $5.13^{* *}$ & 0.05 & 0.3 \\
Cross $\times$ stress & 2 & 0.045 & $16.41^{*}$ & $1.58^{*}$ & 0.06 & 0.15 \\
Cross $\times$ pop $\times$ stress & 6 & 0.12 & 4.87 & 0.42 & 0.09 & 0.04 \\
Fam (pop) $\times$ cross & 27 & $0.11^{*}$ & $7.77^{*}$ & $11.44^{* *}$ & 0.09 & 0.3 \\
Fam(pop) $\times$ stress & 54 & 0.07 & 4.47 & 12.47 & 0.09 & 0.36 \\
Cross $\times$ fam $($ pop) $\times$ stress & 54 & 0.06 & 3.97 & 10.82 & 0.09 & 0.27 \\
Error (d.f.) & & $31.18(526)$ & $22.58(526)$ & $121.9(524)$ & $39.25(524)$ & $95.46(437)$ \\
\hline
\end{tabular}

$* P<0.05, * * P<0.01, * * * P<0.001$.

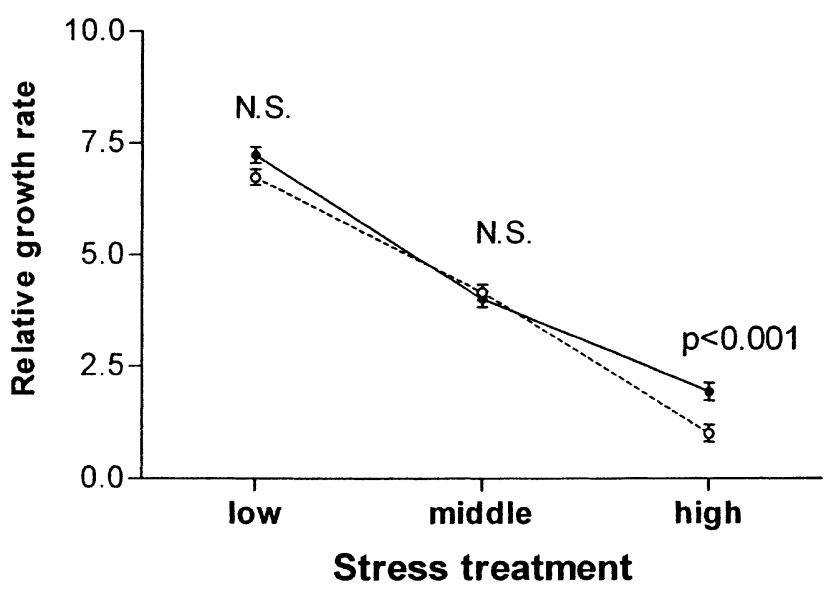

Fig. 3 Mean relative growth rate $( \pm \mathrm{SE})$ for inbred plants (open circles) and outbred plants (full circles) for low, middle and high stress levels, in Crepis sancta. Significance of comparisons of means ( $t$-test) are indicated on the figure.

(Tukey test, $P<0.01$ ). The population factor was significant and the population $\times$ cross interaction was nearly significant $(P=0.07)$ due to population 3 in which inbreeding had no effect, whereas RGR in other populations diminished with inbreeding. The family (pop) $\times$ cross interaction was also significant.

The number of heads was significantly affected by stress and inbreeding. The cross $\times$ stress treatment interaction was also significant, with a higher difference between inbred and noninbred progeny at high stress (Fig. 4). Family(pop) was significant as well as the family (pop) $\times$ cross interaction. The final above-ground dry biomass was significantly affected by stress $(P<0.001)$ and by cross $(P<0.001)$. The significant

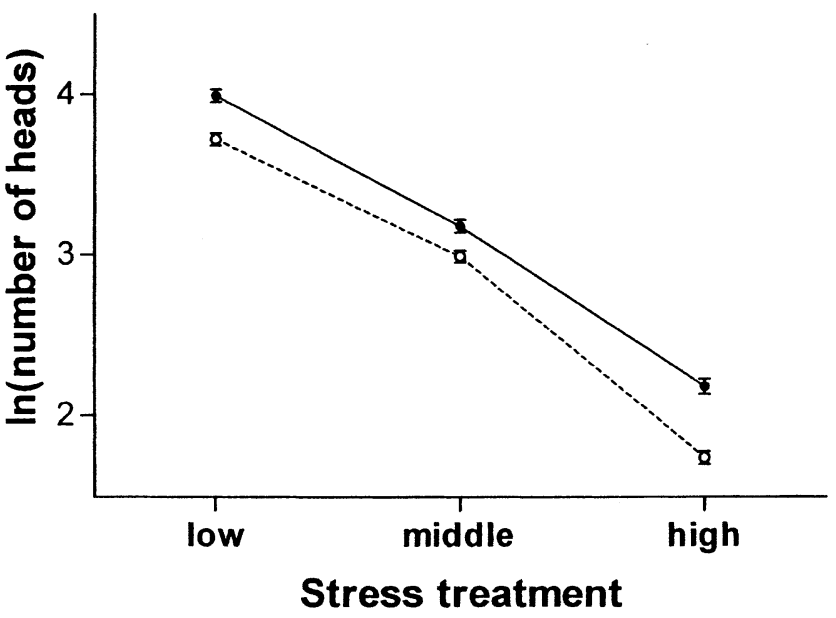

Fig. 4 Mean number of heads produced $( \pm$ SE) for inbred plants (open circles) and outbred plants (full circles) for low, middle and high stress levels, in Crepis sancta.

population effect $(P<0.01)$ reflected a lower biomass in the southern populations compared to populations at the limit of the range. Seed set weight per head was significantly lower in inbred plants $(P<0.001)$. Stressed plants also had significantly reduced seed set weight per head $(P<0.001)$. The population effect was also significant $(P<0.05)$ and showed the same trend as final biomass. Population $\times$ cross interaction was significant $(P<0.05)$ because inbreeding depression for this character was different among populations (inbred and outbred did not differ significantly for population 3 ).

As the family (pop) $\times$ cross interaction was significant for many factors (the date of first flowering, RGR and the number of heads), we checked graphically if the 


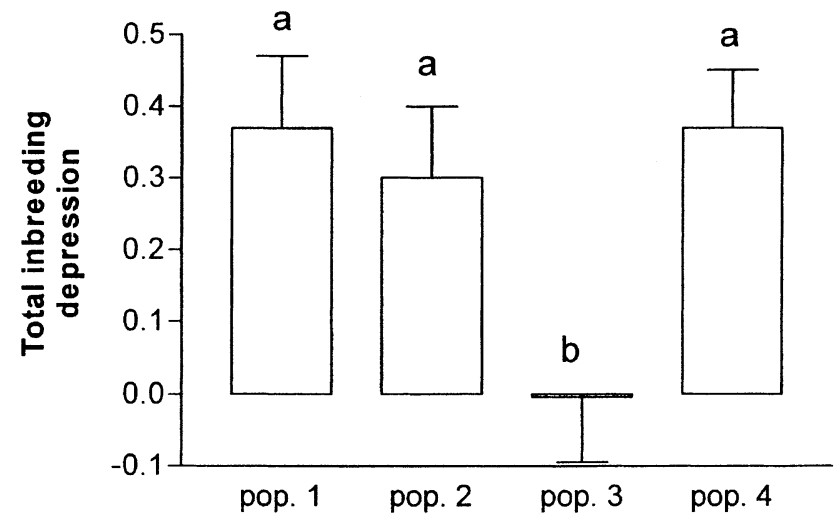

Fig. 5 Mean total inbreeding depression $( \pm \mathrm{SE})$ for the four populations. The bar with a different letter differs significantly (Tukey-test, $P<0.05$ ).

interaction concerned the same families for the three response variables, but no trend was observed.

Total inbreeding depression showed a significant effect of the population factor $\left(F_{3,81}=3.61, P<0.05\right.$, Fig. 5) but neither stress treatment nor stress treatment $\times$ population interactions were significant. An important result is that $\delta$ did not differ significantly from zero for population 3 (Tukey test, $P=0.96$ ), indicating the absence of inbreeding depression in this population, whilst comparisons of means showed that population 3 differed significantly from the other populations (Tukey test, $P<0.01)$.

\section{Discussion}

\section{Effect of drought stress on inbreeding depression components}

Our experimental protocol based on the predawn water potential was effective and provided three different levels of stress conditions. Indeed, for all the measurements made during this experiment, the performances (except mortality) for three levels of stress differed significantly from each other. Inbreeding depression was found in characters correlated with fitness in these experiments. Survival of inbred plants was lower than survival for outbred plants. Though the effect of inbreeding was weak for this character, it was equivalent to that found in a field study in the absence of competition (Cheptou et al., 2000). The number of heads, final biomass and seed weight were also clearly affected by inbreeding. Total inbreeding depression was significantly different from zero (except for population 3 ) but relatively weak $(\delta \approx 0.35)$, compared to what has been found in allogamous plants for these stages of the life cycle (Husband \& Schemske, 1996). However, only survival, the RGR and the number of heads showed a significant cross $\times$ stress treatment interaction, indicating that the effects of inbreeding changed with the level of drought stress.

Nevertheless for survival, low and middle levels of stress resulted in a more pronounced, though very weak, inbreeding depression than the high level of stress (Table 3) i.e. contrary to the expectation. Norman et al. (1995) have found a similar result (lower inbreeding depression in stressful conditions) for Schiedea lydgatei. Conversely, inbreeding depression for the number of heads and RGR was more pronounced at the high stress level, which agrees with expectations. These results can be compared to those obtained by Hauser \& Loeschke (1996), who found a significant and positive effect of drought stress on inbreeding depression for survival, but a nonsignificant effect for fecundity. The different responses in terms of mortality between their work and our results can be attributed to the experimental protocol. Hauser \& Loeschke (1996) produced drought stress by varying the frequency of watering. Thus their experiment probably tested the consequences of the fluctuations in water availability, rather than the effect of stress itself. When environmental conditions vary, development of outbred genotypes is less affected than inbred genotypes (Falconer, 1989). In the present work, the three levels of drought did not vary during the experiment (see Fig. 1) and did not produce any excess mortality for inbred plants (compared to outbreds) at the high stress level, which may explain why our results differ from those of Hauser \& Loeschke (1996).

Previous studies on the effects of abiotic stress, such as drought (Hauser \& Loeschke, 1996), fertilizer level (Norman et al., 1995) or field conditions without competition (Johnston, 1992), did not produce a large effect on inbreeding depression. These results are therefore similar to that found in C. sancta. In contrast, many papers have shown a general trend for an increased inbreeding depression with the intensity of competition (Dudash, 1990; Schmitt \& Ehrhardt, 1990; Wolfe, 1993). In a previous study with Crepis sancta, we showed also that interspecific competition in field conditions greatly increased inbreeding depression (Cheptou et al., 2000). The contrasting results between the two types of experiments may be explained by the mechanisms of competition. For instance, relative growth rate determines biomass and seed set, especially for annual and colonizing plants (Grime, 1979). A plant with a low RGR (as inbreds in our experiment) will grow slowly, but the effects on fitness will probably be weak in noncompetitive conditions. However, when these plants grow in competition with plants with a higher growth rate, such as outbred 
plants, then the relative fitness of the inbreds will greatly decrease because outbreds will use resources faster. Consequently, we would expect that a low RGR in inbred plants greatly decreases the relative fitness when they are in competition. Clearly, new experiments are needed to document this problem.

\section{Among-population variation in inbreeding depression}

Populations 1, 2 and 4 showed very similar trends for inbreeding depression estimates. Total inbreeding depression for the three populations differed significantly from zero. Conversely, population 3 showed no detectable inbreeding depression. As mentioned in the introduction, we expected that inbreeding depression would be lower in populations with higher self-compatibility, under the partial dominance hypothesis.

Population 3 had higher seed/floret ratios in selfing. In particular, the ratio in spontaneous self-pollination was significantly higher than the ratios in population 1 and 4 , and almost significantly higher $(P=0.07)$ than the ratio of population 2 . The absence of inbreeding depression in population 3 suggests that, in accordance with the partial dominance hypothesis, deleterious mutations have been purged because of higher historical inbreeding in this population. This pattern has been observed in different populations with various selfing rates, but the variation in inbreeding depression was lower in spite of a higher selfing rate variation (Holtsford \& Ellstrand, 1990). Nevertheless, evidence for a purging process with increasing selfing rate does not hold true in every case (Byers \& Waller, 1999). Willis (1999) showed that lethal or highly deleterious mutations are easy to purge, but mildly deleterious mutations are not, even if selfing rate is high. In Crepis sancta, between-population variations in self-fertility are low and reflect a low inbreeding variation among populations. It is likely that population 3 had been purged of highly deleterious mutations and this could explain the differences from the other populations. Population 4 exhibited a relatively high seed/floret ratio in hand self-pollination but a small ratio in spontaneous pollination. Yet its inbreeding depression was similar to the inbreeding depression in Mediterranean populations. However, spontaneous self-pollination was infrequent and this parameter is therefore more relevant to infer the selfing rate in natural populations. Indeed, selfing probably occurs in the absence of active pollination (spontaneous pollination) and geitonogamy is probably low in these populations, because there is no lack of partners for cross-pollination.

\section{Implications for mating systems in natural populations}

The absence of inbreeding depression in population 3 and a weak inbreeding depression for the three others are very unlikely for an allogamous species and inconsistent with the maintenance of a partial selfincompatibility system. A necessary condition for the maintenance of a self-incompatibility system is a strong inbreeding depression, i.e. $\delta>0.5$ (Charlesworth, 1988), which was not found in the present experiment. This suggests that inbreeding depression was probably underestimated here. Indeed, a new experiment with population 3 (using the same families and the same crosses), showed that significant inbreeding depression can be detected ( $\delta \approx 0.5$ compared to $\delta=0$ in the present study) when competition occurs between inbred and outbred plants (Cheptou, unpubl. data). This result agrees with the mechanism of a faster development of outbred plants proposed above. Thus, by neglecting competitive interaction we probably underestimated the effect of inbreeding in natural populations.

\section{References}

ASChManN, H. 1973. Distribution and peculiarity of Mediterranean ecosystems. In: Di Castri, F. and Mooney, H. A. (eds) Mediterranean Type Ecosystems, pp. 11-19. Ecological studies 7, Springer Verlag, Berlin.

BYERS, D. L. AND WALLER, D. M. 1999. Do plant populations purge their genetic load? Effects of population size and mating system history on inbreeding depression. Ann. Rev. Ecol. Syst., 30, 479-513.

CHARLESWORTH, D. 1988. Evolution of homomorphic sporophytic self-incompatibility. Heredity, 60, 445-453.

CHARLESWORTH, D. AND CHARLESWORTH, B. 1987. Inbreeding depression and its evolutionary consequences. Ann. Rev. Ecol. Syst., 18, 237-268.

Chassagne, M. 1941. Pterotheca nemausensis Cass plante méridionale en migration rapide et continue dans la direction du Nord. Revue Sci. Naturelles d'Auvergne, 7, 16-26.

CHEPTOU, P. O., IMBERT, E., LEPART, J. AND ESCARRÉ, J. 2000. Effects of competition on lifetime estimates of inbreeding depression in the outcrossing plant Crepis sancta (Asteraceae). J. Evol. Biol., 13, 522-531.

CORILliON, R. 1950. Lagoseris sancta (L.) K. Maly (Pterotheca nemausensis Cass): les progrès récents de sa migration dans le Massif Armoricain. C. R. Somm. Séances Soc. Biogeog., 236, 94-100.

CRAWLEY, J. M. 1993. GLIM for Ecologists. Blackwell Scientific Publications, Oxford.

CRUiziat, P., TYREE, M. T., BODET, C. AND LOGUllo, M. A. 1980. The kinetics of rehydratation of detached sunflower leaves following substantial water loss. New Phytol., 84, 293-306. 
DARWIN, C. R. 1876. The Effects of Cross and Self Fertilization in the Vegetable Kingdom. Murray, London.

DUDASH, M. R. 1990. Relative fitness of selfed and outcrossed progeny in a self-incompatible, protandrous species, Sabatia angularis L. (Gentianaceae): a comparison in three environments. Evolution, 44, 1129-1139.

FALCONER, D. S. 1989. Introduction to Quantitative Genetics. Third Edition. Longman, London.

FISHER, R. A. 1941. Average excess and average effect of a gene substitution. Ann. Eugen., 11, 53-63.

GRIME, J. P. 1979. Plant Strategy and Vegetation Processes. John Wiley \& Sons, London.

HAUSER, T. P. AND LOESCHKe, V. 1996. Drought stress and inbreeding depression in Lychnis flos-cuculi (Caryophyllaceae). Evolution, 50, 1119-1126.

HOLTSFORD, T. P. AND ELLSTRAND, N. C. 1990. Inbreeding depression in Clarkia temploriensis (Onagraceae) populations with different natural outcrossing rates. Evolution, 44, 2031-2046.

HUSBAND, B. AND SCHEMSKE, D. W. 1996. Evolution of the magnitude and timing of inbreeding depression in plants. Evolution, 50, 54-70.

IMBERT, E., ESCARRÉ, J. AND LEPART, J. 1996. Achene dimorphism and among-population variation in Crepis sancta (Asteraceae). Int. J. Plant Sci., 157, 309-315.

JOHNSTON, M. O. 1992. Effects of cross and self-fertilization on progeny fitness in Lobelia cardinalis and L. siphilitica. Evolution, 46, 688-702.

JOHNSTON, M. O. AND SCHOEN, D. J. 1994. On the measurement of inbreeding depression. Evolution, 48, 1735-1741.

MAYER, S. S., CHARLESWORTH, D. AND MEYERS, B. 1996. Inbreeding depression in four populations of Collinsia heterophylla Nutt. (Scrophulariaceae). Evolution, 50, 879-891.
NORMAN, J. K., SAKAI, A. K., WELlER, S. G. AND DAWSON, T. E. 1995. Inbreeding depression in morphological and physiological traits of Schiedea lydgatei (Caryophyllaceae) in two environments. Evolution, 49, 297-306.

SAS INSTITUTE INC. 1989. SAS/STAT User's Guide, version 6, 4 th edn. SAS Institute Inc., Cary, NC.

SCHMITT, J. AND EHRHARDT, D. W. 1990. Enhancement of inbreeding depression by dominance and suppression in Impatiens capensis. Evolution, 44, 269-278.

SlAtyer, R. O. 1967. Plant Water Relationships. Academic Press, New York.

SOKAL, R. R. AND ROHLF, F. J. 1995. Biometry, 3rd edn. W. H. Freeman, New York.

SOltis, D. E. AND SOlTIS, P. S. 1989. Isozymes in Plant Biology. Dioscorides Press, New York.

THEllung, A. 1910. La flore adventice de Montpellier. Mem. Soc. Nat. Sci. Nat. Maths. Cherbourg, 37, 57-278.

UYENOYAMA, M., HOLSINGER, K. E. AND WALlER, D. M. 1993. Ecological and genetic factors directing the evolution of self fertilization. Oxford Surveys Evol. Biol., 9, 327-381.

WILlis, J. H. 1999. The role of genes of large effect on inbreeding depression in Mimulus guttatus. Evolution, 53, 1678-1691.

WOLFE, L. M. 1993. Inbreeding depression in Hydrophyllum appendiculatum: role of maternal effects, crowding, and parental mating history. Evolution, 47, 374-386.

WRIGHT, s. 1977. Evolution and the Genetics of Populations. Vol. 3. Experimental Results and Evolutionary Deductions. University of Chicago Press, Chicago. 